\title{
Prognostic value of pretreatment platelet counts in lung cancer: a systematic review and meta-analysis
}

\author{
Yuan Yuan ${ }^{1+}$, Hai Zhong ${ }^{2 \dagger}$, Liang Ye ${ }^{1}$, Qian $\mathrm{Li}^{1}$, Surong Fang ${ }^{1}$, Wei Gu${ }^{1}$ and Yingying Qian ${ }^{1 *}$
}

\begin{abstract}
Background: The prognostic value of elevated pretreatment platelet counts remains controversial in lung cancer patients. We performed the present meta-analysis to determine its precise role in these patients.

Methods: We employed a multiple search strategy in the PubMed, EMBASE and Cochrane Library databases to identify eligible studies. Disease-free survival (DFS)/progression-free survival (PFS)/time to progression (TTP) and overall survival (OS) were used as outcomes with hazard ratios (HRs) and 95\% confidence intervals (Cls). Heterogeneity among the studies and publication bias were also evaluated.

Results: A total of 40 studies including 16,696 lung cancer patients were eligible for the analysis. Overall, the pooled analysis showed that compared with normal platelet counts, elevated pretreatment platelet counts were associated with poorer OS (HR $=1.54,95 \% \mathrm{Cl}: 1.37-1.72, P<0.001)$ and poorer DFS/PFS/TTP $(H R=1.62,95 \% \mathrm{Cl}: 1.33-1.98, P<$ 0.001 ) in patients with lung cancer. In subgroup analyses, elevated pretreatment platelet counts were also associated with poorer OS and DFS/PFS/TTP in most subgroups. There was no evidence of publication bias.
\end{abstract}

Conclusions: This meta-analysis revealed that elevated pretreatment platelet counts were an independent predictor of OS and DFS/PFS/TTP in lung cancer patients. Large-scale prospective studies and a validation study are warranted.

Keywords: Lung cancer, Platelet count, Prognosis, Meta-analysis

\section{Background}

According to the Global Cancer Statistics 2018, lung cancer is the most common cancer (11.6\% of total cancer cases) and the leading cause of cancer deaths $(18.4 \%$ of the total cancer deaths) worldwide [1]. Non-small-cell lung cancer (NSCLC), the leading type of lung cancer, accounts for $80 \%$ of all cases. Although various therapies, such as surgery, radiotherapy, chemotherapy, targeted therapy, and the rising immunization therapy have emerged, they exhibit limited effects on lung cancer, and the prognosis of patients remains unsatisfactory, with five-year survival rates of $6.3 \%$

\footnotetext{
* Correspondence: qianyyvic@126.com

${ }^{\dagger}$ Yuan Yuan and Hai Zhong contributed equally to this work.

${ }^{1}$ Department of Respiratory and Critical Care Medicine, Nanjing First Hospital, Nanjing Medical University, 68 Changle road, Nanjing 210006, Jiangsu, China Full list of author information is available at the end of the article
}

for small cell lung cancer (SCLC) and 18.2\% for NSCLC [2-4]. Compared to treating advanced cancer, prevention is much better. Therefore, it is important to investigate novel prognostic factors to improve treatment therapies.

In the 1960s, Richard B. et al. suggested that platelets were correlated with cancer [5]. Tumour cells can secrete platelet agonists to induce platelet aggregation, which results in thrombocytosis by producing thrombopoietic cytokines such as interleukin (IL)-1, IL-3, IL-11, and particularly tumour-derived IL-6 [6-9]. Many studies have shown that thrombocytosis plays a role in cancer genesis and development $[10,11]$. Increasing evidence has indicated that platelet count correlates with prognosis in various malignancies, such as lung, renal, gastric, colorectal and hepatocellular cancer and is considered a hallmark of

(c) The Author(s). 2020 Open Access This article is licensed under a Creative Commons Attribution 4.0 International License, which permits use, sharing, adaptation, distribution and reproduction in any medium or format, as long as you give appropriate credit to the original author(s) and the source, provide a link to the Creative Commons licence, and indicate if changes were made. The images or other third party material in this article are included in the article's Creative Commons licence, unless indicated otherwise in a credit line to the material. If material is not included in the article's Creative Commons licence and your intended use is not permitted by statutory regulation or exceeds the permitted use, you will need to obtain permission directly from the copyright holder. To view a copy of this licence, visit http://creativecommons.org/licenses/by/4.0/ The Creative Commons Public Domain Dedication waiver (http://creativecommons.org/publicdomain/zero/1.0/) applies to the data made available in this article, unless otherwise stated in a credit line to the data. 
cancer [12-16]. Additionally, the platelet count is convenient to perform, less expensive, and easily available. However, the current opinions about the correlation between platelet count and lung cancer prognosis are controversial. Some studies have identified that platelet count is a poor prognostic factor in NSCLC, while some suggest that platelet count has no association with lung cancer [11, 17-19]. Therefore, we conducted this meta-analysis to further investigate the prognostic value of pretreatment platelet counts for survival in lung cancer patients.

\section{Methods}

\section{Search strategy}

This meta-analysis was conducted and reported in accordance with the Preferred Reporting Items for Systematic Reviews and Meta-Analyses (PRISMA) guidelines (Additional file 1). A comprehensive search was conducted by searching databases including the PubMed, EMBASE and Cochrane Library databases using the following terms: ("thrombocytosis" or "thrombocytosis" or "thrombocythemia" or "platelet count" or "blood platelets" or "platelets") and ("lung carcinoma" or "lung cancer" or "lung tumor" or "lung neoplasm") and ("prognosis" or "prognostic" or "survival" or "outcome") up to December 31, 2017.

\section{Selection criteria}

The inclusion criteria for this meta-analysis were as follows: (1) the diagnosis of lung cancer was confirmed pathologically; (2) platelet count was measured before treatment; (3) hazard ratios (HRs) and their 95\% confidence intervals (CIs) for platelet count were reported; (4) the cut-off value of platelet count was reported; and (5) the relationship between overall survival (OS) or diseasefree survival (DFS)/progression-free survival (PFS)/time to progression (TTP) and platelet count was evaluated.

\section{Exclusion criteria}

Articles were excluded if they met the following criteria: (1) articles were reviews, case reports, letters, editorials, or conference abstracts; (2) articles that were not written in English; (3) articles missing key information for evaluating the $\mathrm{HR}$ and its $95 \% \mathrm{CI}$; (4) studies based on cancer cells or animal models and irrelevant studies; and (5) studies by the same authors with similar or overlapping data. Two reviewers assessed the candidate articles independently. Any disputes were settled through discussion.

\section{Data extraction and quality assessment}

Two reviewers independently extracted data from the selected literature and completed quality assessments. The

Records identified through database searching $(\mathrm{n}=2395)$

Pubmed :1052; Embase:1343

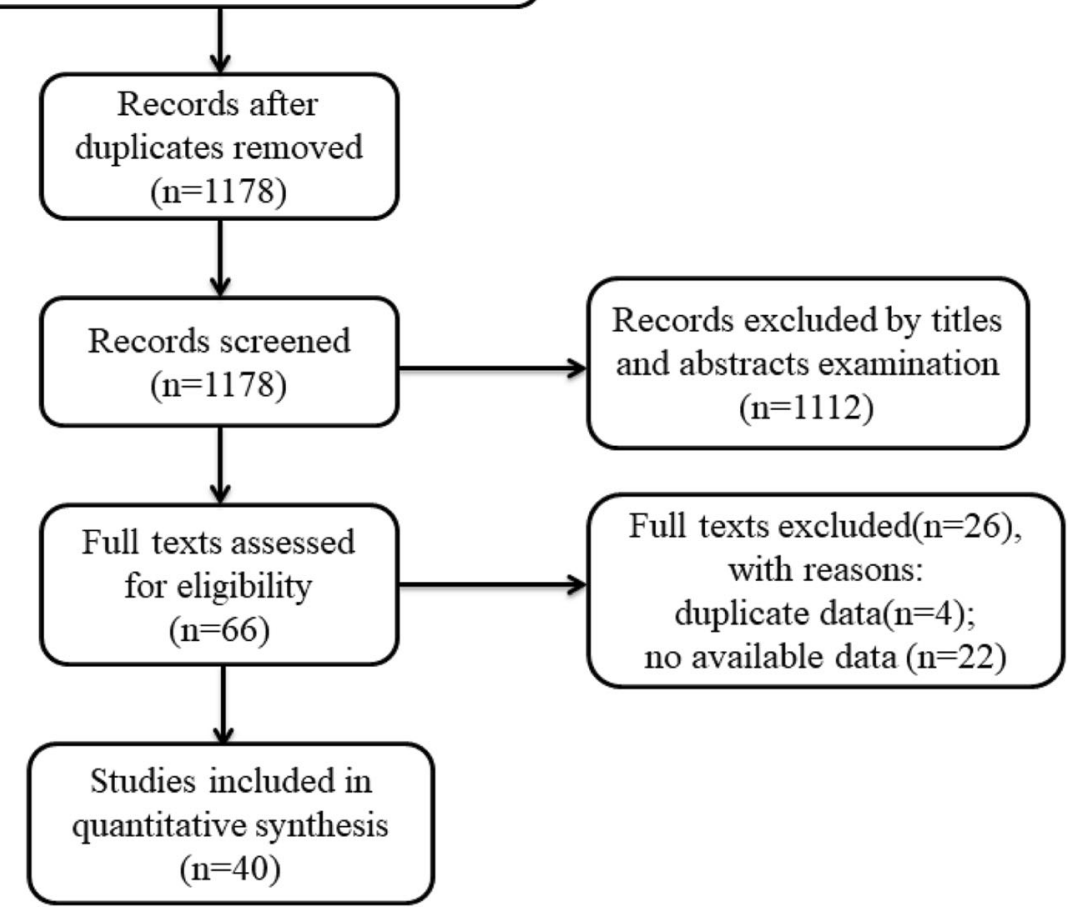

Fig. 1 Flow chart representing the search steps and study selection 
Table 1 The basic characteristics of included studies in the meta-analysis

\begin{tabular}{|c|c|c|c|c|c|c|c|c|c|c|c|}
\hline \multirow[t]{2}{*}{ Author } & \multirow[t]{2}{*}{ Year } & \multirow[t]{2}{*}{ Country } & \multirow[t]{2}{*}{ Cases } & \multirow[t]{2}{*}{ Tumor type } & \multirow{2}{*}{$\begin{array}{l}\text { Clinical } \\
\text { stage }\end{array}$} & \multirow{2}{*}{$\begin{array}{l}\text { Cut-off } \\
\text { value }\end{array}$} & \multirow[t]{2}{*}{ Outcome } & \multicolumn{2}{|l|}{ OS } & \multicolumn{2}{|c|}{ DFS/PFS/TTP } \\
\hline & & & & & & & & $\mathrm{U} / \mathrm{M}$ & $\mathrm{HR}(95 \% \mathrm{Cl})$ & $\mathrm{U} / \mathrm{M}$ & $\mathrm{HR}(95 \% \mathrm{Cl})$ \\
\hline Pedersen LM & 1996 & Denmark & 1115 & $\mathrm{NSCLC}+\mathrm{SLCL}$ & I-IV & 400 & OS & M & $4.24(1.50-12.72)$ & & \\
\hline $\operatorname{Cox} G$ & 2000 & UK & 175 & NSCLC & $|-||| A$ & 320 & OS & M & $1.69(1.12-2.56)$ & & \\
\hline Suzuki M & 2002 & Japan & 99 & NSCLC & I-IV & 231 & OS & M & $3.04(1.08-8.55)$ & & \\
\hline Swinson DE & 2003 & United Kingdom & 175 & NSCLC & $|-||| A$ & 314 & OS & M & $1.64(1.13-2.39)$ & & \\
\hline Bremnes RM & 2003 & Norway & 436 & SCLC & - & 150 & OS & M & $3.10(1.40-7.20)$ & & \\
\hline Unsal E & 2004 & Turkey & 58 & $\mathrm{NSCLC}+\mathrm{SLCL}$ & I-IV & 400 & OS & M & $0.96(0.54-1.72)$ & & \\
\hline Aoe K & 2004 & Japan & 611 & NSCLC+ SLCL & I-IV & 400 & OS & M & $1.29(1.02-1.64)$ & & \\
\hline Prévost S & 2006 & Canada & 120 & NSCLC & Not Report & 340 & OS & M & $1.50(1.0-2.30)$ & & \\
\hline Tomita M & 2008 & Japan & 240 & NSCLC & I-IV & 400 & OS & M & $1.46(1.01-2.01)$ & & \\
\hline $\begin{array}{l}\text { Gonzalez } \\
\text { Barcala FJ }\end{array}$ & 2010 & Spain & 365 & $\mathrm{NSCLC}+\mathrm{SCLC}$ & I-IV & 258 & OS & M & $1.15(0.90-1.47)$ & & \\
\hline $\begin{array}{l}\text { Gonzalez } \\
\text { Barcala FJ }\end{array}$ & 2010 & Spain & 294 & $\mathrm{NSCLC}+\mathrm{SCLC}$ & I-IV & 381 & OS & M & $1.09(0.82-1.46)$ & & \\
\hline Luo J & 2012 & USA & 110 & NSCLC & I-IV & 300 & OS & M & $2.86(1.48-5.54)$ & & \\
\hline Holgersson G & 2012 & Sweden & 823 & NSCLC & I-IV & 350 & OS & M & $1.35(1.12-1.62)$ & & \\
\hline Yu D & 2013 & China & 510 & NSCLC & $|-|||$ & 300 & OS,DFS & M & $1.69(1.01-2.38)$ & M & $1.57(1.01-2.45)$ \\
\hline Maráz A & 2013 & Hungary & 398 & $\mathrm{NSCLC}+\mathrm{SLCL}$ & I-IV & 400 & OS & M & $1.58(1.14-2.18)$ & & \\
\hline Kim KH & 2014 & Korea & 854 & NSCLC & III-IV & 450 & OS & M & $1.51(1.14-2.00)$ & & \\
\hline Kim M & 2014 & Korea & 199 & NSCLC & $|-|||$ & 400 & OS,DFS & M & $2.98(1.39-6.37)$ & M & $2.47(1.22-5.01)$ \\
\hline Ji Y & 2014 & China & 234 & NSCLC & । & 300 & OS,DFS & M & $3.14(1.23-8.03)$ & M & $5.31(2.75-10.27)$ \\
\hline Zhu JF & 2014 & China & 275 & NSCLC & IV & 300 & OS & M & $1.40(1.00-2.00)$ & & \\
\hline Hong $X$ & 2016 & China & 999 & $\mathrm{SCLC}$ & - & 300 & OS,PFS & M & $1.01(0.87-1.18)$ & M & $0.91(0.70-1.17)$ \\
\hline Gotfrit J & 2016 & Canada & 223 & NSCLC & IIIB-IV & 400 & OS & M & $1.46(1.03-2.09)$ & & \\
\hline Boddu P & 2016 & USA & 571 & NSCLC & I-IV & 450 & OS & M & $1.64(1.05-2.55)$ & & \\
\hline Liu W & 2017 & China & 1120 & NSCLC & $|-||| A$ & 300 & OS,DFS & M & $1.15(0.96-1.39)$ & M & $1.17(0.97-1.40)$ \\
\hline Wang YQ & 2017 & China & 134 & NSCLC & $|-||| A$ & 289 & OS,DFS & M & $2.28(1.43-3.62)$ & U & $1.63(1.01-2.64)$ \\
\hline Holgersson G & 2017 & Sweden & 222 & NSCLC & III & 350 & OS & M & $1.66(1.12-2.48)$ & & \\
\hline Holgersson G & 2017 & Sweden & 99 & NSCLC & IIIB-IV & 350 & OS & M & $1.25(0.71-2.22)$ & & \\
\hline Cui MM & 2017 & China & 270 & NSCLC & $|-|||$ & Not Report & OS & M & $1.00(1.00-1.01)$ & & \\
\hline Ohuchi M & 2017 & Japan & 146 & $\mathrm{NSCLC}+\mathrm{SLCL}$ & I-IV & 244 & OS & M & $1.88(1.13-3.13)$ & & \\
\hline Mandrekar SJ & 2006 & Canada+ USA & 1053 & NSCLC & IIIB-IV & 375 & OS,TTP & U & $1.41(1.24-1.60)$ & U & $1.27(1.11-1.45)$ \\
\hline Altiay $G$ & 2007 & Turkey & 78 & $\mathrm{NSCLC}+\mathrm{SLCL}$ & III-IV & 400 & OS & U & $2.33(1.27-4.26)$ & & \\
\hline Qiu MZ & 2010 & China & 430 & NSCLC & I-IV & 400 & OS & U & $1.09(0.60-1.98)$ & & \\
\hline Liu HB & 2013 & China & 883 & NSCLC & I-IV & 300 & OS & U & $1.30(1.02-1.66)$ & & \\
\hline Du G & 2013 & China & 258 & NSCLC & IIIA-IV & 400 & OS,PFS & U & $4.15(3.09-5.59)$ & U & $3.47(2.60-4.65)$ \\
\hline Zhang $\mathrm{T}$ & 2014 & China & 400 & NSCLC & I-H & 190 & OS,DFS & U & $1.47(0.88-2.45)$ & U & $1.57(1.01-2.45)$ \\
\hline Wu G & 2015 & China & 366 & NSCLC & III-IV & 117.5 & OS,PFS & U & $1.22(0.90-1.65)$ & U & $1.25(0.92-1.69)$ \\
\hline Zhang $\mathrm{H}$ & 2015 & China & 1238 & NSCLC & $|-||| A$ & 300 & OS,DFS & U & $1.38(1.17-1.63)$ & U & $1.38(1.16-1.63)$ \\
\hline Zhang W & 2015 & China & 308 & NSCLC & I-IV & 300 & OS & U & $1.67(1.23-2.27)$ & & \\
\hline Gao L & 2017 & China & 546 & NSCLC & $|-||| A$ & 300 & OS,DFS & U & $1.72(1.35-2.19)$ & U & $1.70(1.33-2.17)$ \\
\hline Li Y & 2014 & China & 126 & NSCLC & III-IV & 200 & PFS & & & M & $1.69(1.16-2.46)$ \\
\hline Lee $S$ & 2017 & Korea & 135 & $\mathrm{NSCLC}$ & IIIB-IV & 400 & OS & U & $1.49(0.80-2.78)$ & & \\
\hline
\end{tabular}


first author name, year of publication, country of origin, number of enrolled patients, tumour type, clinical stage, cut-off value of platelet count, and outcomes were

Table 2 Quality assessment of containing studies using the Newcastle-Ottawa Scale

\begin{tabular}{|c|c|c|c|c|}
\hline Study & Selection & Comparability & Outcome & Total score \\
\hline Pedersen LM & 4 & 1 & 3 & 8 \\
\hline Cox G & 4 & 2 & 2 & 8 \\
\hline Suzuki M & 4 & 0 & 2 & 6 \\
\hline Swinson DE & 4 & 0 & 2 & 6 \\
\hline Bremnes RM & 4 & 0 & 2 & 6 \\
\hline Unsal E & 4 & 1 & 2 & 7 \\
\hline Aoe K & 4 & 0 & 2 & 6 \\
\hline Mandrekar SJ & 4 & 1 & 2 & 7 \\
\hline Prévost S & 4 & 0 & 2 & 6 \\
\hline Altiay G & 4 & 0 & 2 & 6 \\
\hline Tomita M & 4 & 2 & 2 & 8 \\
\hline Qiu MZ & 4 & 2 & 2 & 6 \\
\hline Gonzalez Barcala FJ & 4 & 2 & 2 & 8 \\
\hline Gonzalez Barcala FJ & 4 & 2 & 2 & 8 \\
\hline Luo J & 4 & 1 & 2 & 7 \\
\hline Holgersson G & 4 & 1 & 2 & 7 \\
\hline Yu D & 4 & 2 & 2 & 8 \\
\hline Liu HB & 4 & 0 & 2 & 6 \\
\hline Maráz A & 4 & 0 & 2 & 6 \\
\hline Du G & 4 & 1 & 2 & 7 \\
\hline Kim KH & 4 & 2 & 1 & 7 \\
\hline Kim M & 4 & 2 & 2 & 8 \\
\hline Zhang $\mathrm{T}$ & 4 & 0 & 3 & 7 \\
\hline Ji Y & 4 & 1 & 2 & 7 \\
\hline Zhu JF & 4 & 2 & 2 & 8 \\
\hline Wu G & 4 & 0 & 2 & 6 \\
\hline Zhang $\mathrm{H}$ & 4 & 1 & 2 & 7 \\
\hline Zhang W & 4 & 0 & 3 & 7 \\
\hline Hong $X$ & 4 & 0 & 2 & 6 \\
\hline Gotfrit J & 4 & 0 & 2 & 6 \\
\hline Boddu P & 4 & 1 & 2 & 7 \\
\hline Gao L & 4 & 2 & 3 & 9 \\
\hline Liu W & 4 & 2 & 2 & 8 \\
\hline Wang YQ & 4 & 1 & 2 & 7 \\
\hline Lee $\mathrm{S}$ & 4 & 0 & 2 & 6 \\
\hline Holgersson G & 4 & 0 & 2 & 6 \\
\hline Holgersson G & 4 & 0 & 2 & 6 \\
\hline Cui MM & 4 & 0 & 3 & 7 \\
\hline Ohuchi M & 4 & 0 & 2 & 6 \\
\hline Li Y & 4 & 2 & 1 & 7 \\
\hline
\end{tabular}

included as publication characteristics. HRs for OS and PFS and their 95\% CIs were collected as result data. If the study provided both univariate analysis and multivariate analysis results, we took the results of multivariate analysis because multivariate analyses exclude correlated confounding factors and are more accurate. In addition, only one study (Holgersson G, 2012) categorized platelet count into three groups according to cut-off values (platelet count $<150,150<$ platelet count $<350$, and platelet count $>350$ ), and there were two HRs for OS. We extracted the HR that compared the group with $150<$ platelet count $<$ 350 and the group with platelet count $>350$. We used the Newcastle-Ottawa Scale (NOS) scoring system to assess the quality of the included articles [20]. Two reviewers independently evaluated the quality of each included study. The judgement criteria include three aspects of evaluation: selection, comparability, and outcome between the case group and control group. Studies with higher scores had higher quality.

\section{Statistical analysis}

The meta-analysis was conducted by STATA 12.0 software (Stata Corp, College Station, TX, USA). HRs and corresponding 95\% CIs were used to analyse the association between platelet count and lung cancer. Cochrane's Q test and the I2 statistic were used to evaluate the heterogeneity among the included studies [21]. I $>50 \%$ or $P$-value $<0.05$ indicated heterogeneity in the studies [22, 23], and a random-effects model was adopted; otherwise, a fixedeffects model was used. Moreover, subgroup analysis was conducted to detect the potential source of heterogeneity. A $P$-value less than 0.05 indicated statistical significance. Publication bias was evaluated by Begg's test and Egger's regression test [24]. Additionally, sensitivity analysis was performed to check the stability of the results [25].

\section{Results}

Study characteristics

A flow diagram demonstrating the search procedure is illustrated in Fig. 1. After the original search, 2395 records were retrieved from the electronic databases. First, we removed duplications, and 1178 records remained. Among them, another 1112 records were also excluded after examining the titles and abstracts. Next, the remaining 66 full texts were assessed for eligibility. Of these, 26 studies were excluded on account of duplicate dates and incomplete data. Ultimately, 40 studies including a total of 16,696 participants met the criteria and were enrolled in this meta-analysis [17-19, 26-60].

The characteristics of the patients included are presented in Table 1. All included studies were published between 1976 and 2017. As shown in Table 1, 40 studies were included in the meta-analysis, 30 studies on NSCLC, 2 studies on SCLC, and 8 studies on all tumour 
types. Twenty-three studies were performed in Asian populations and 16 in Caucasian populations, while one study did not report the race of the participants. In terms of the cut-off value of platelet count, 8 studies used $<300$ as the cut-off value, 18 studies used $300-400$ as the cut-off value, one study did not report the cut-off value of platelet count, and the remaining 13 studies considered $\geq 400$ as the cut-off value. There were 39 studies evaluating the association between OS and platelet count, while 13 studies evaluated the DFS/PFS/TTP outcome. All 40 studies reported the HR and 95\% CI directly. Additionally, the quality of the studies was assessed by NOS, as shown in Table 2 .

\section{Meta-analysis}

OS

There were 39 studies including 16,570 patients providing data on the prognostic role of platelet count for OS in lung cancer. The results indicate that elevated platelet counts were associated with poorer OS in lung cancer patients $(\mathrm{HR}=1.54,95 \%$ CI: 1.37-1.72, $P<0.001$, Fig. $2 \mathrm{a})$. Then, we conducted subgroup analysis for further investigation, and the results are summarized in Table 3. In the subgroup stratified by ethnicity, we observed that elevated platelet counts predicted poor OS in Asian populations $(\mathrm{HR}=1.54,95 \% \mathrm{CI}: 1.32-1.8, P<0.001)$, while that in non-Asian populations had no significance $(P=$ 0.063). Based on clinical stage, a significant association between elevated platelet counts and OS was found in stage I-III $(\mathrm{HR}=1.52,95 \% \mathrm{CI}: 1.22-1.89, P<0.001)$ and stage $>$ III $(\mathrm{HR}=1.7,95 \% \mathrm{CI}: 1.26-2.29, P<0.001)$. An obvious association between elevated platelet counts and OS was observed when integrating the data from 28 studies in which OS was evaluated with multivariate analyses $(\mathrm{HR}=1.47,95 \% \mathrm{CI}: 1.31-1.66, P<0.001)$. In terms of the cut-off value, the subgroup analysis confirmed that increased platelet counts were a negative predictor in patients with cut-off values $<300(\mathrm{HR}=1.64$, 95\% CI: $1.25-2.15, P<0.05)$ and with cut-off values $>400$ $(\mathrm{HR}=1.73,95 \% \mathrm{CI}: 1.35-2.21, P<0.001)$ Additionally, high platelet counts still predicted worse OS in patients with lung cancer, regardless of the subtype of lung cancer (SCLC or NSCLC).

\section{DFS/PFS/TTP}

The meta-analysis of DFS/PFS/TTP, which contained 13 studies with 7183 patients, indicated that cancer patients with high platelet counts had significantly shorter DFS/ PFS/TTP than those with low platelet counts $(\mathrm{HR}=1.62$, 95\% CI: 1.33-1.98, $P<0.001$, Fig. $2 \mathrm{~b})$. A random-effects model was used. Subgroup analysis was performed, and the results are shown in Table 3. The results suggested that in the subgroup analysis, elevated platelet count was a negative predictor in the Asian population subgroup $(P<0.001)$, multivariate analysis subgroup $(P<0.001)$, stage III-IV disease subgroup $(P<0.001)$, and $300 \leq$ cutoff value $<400$ subgroup $(P<0.001)$.

In the following four subgroups, patients with elevated pretreatment platelet counts had similar DFS/PFS/TTP compared with patients with normal platelet counts: a

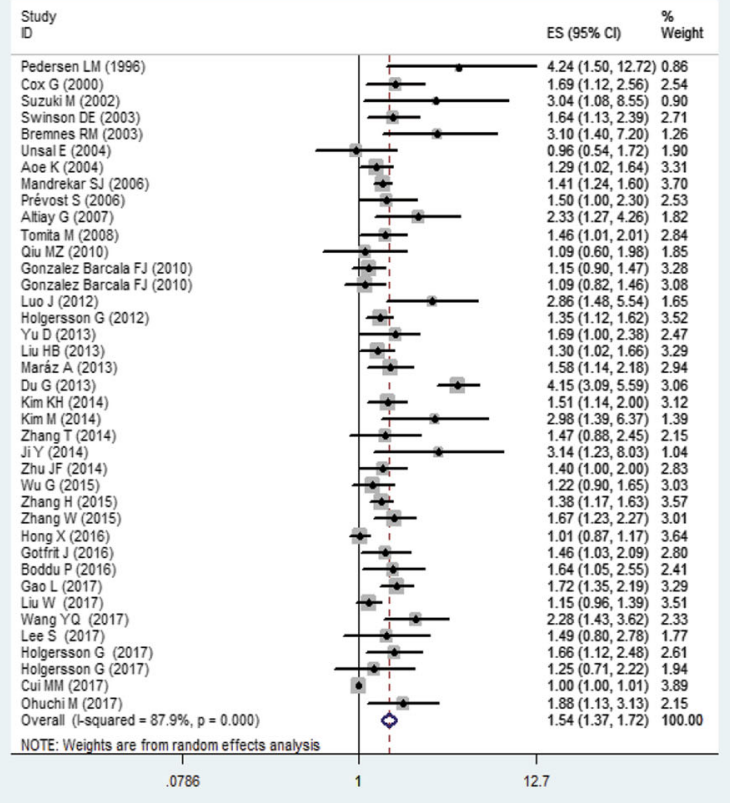

b

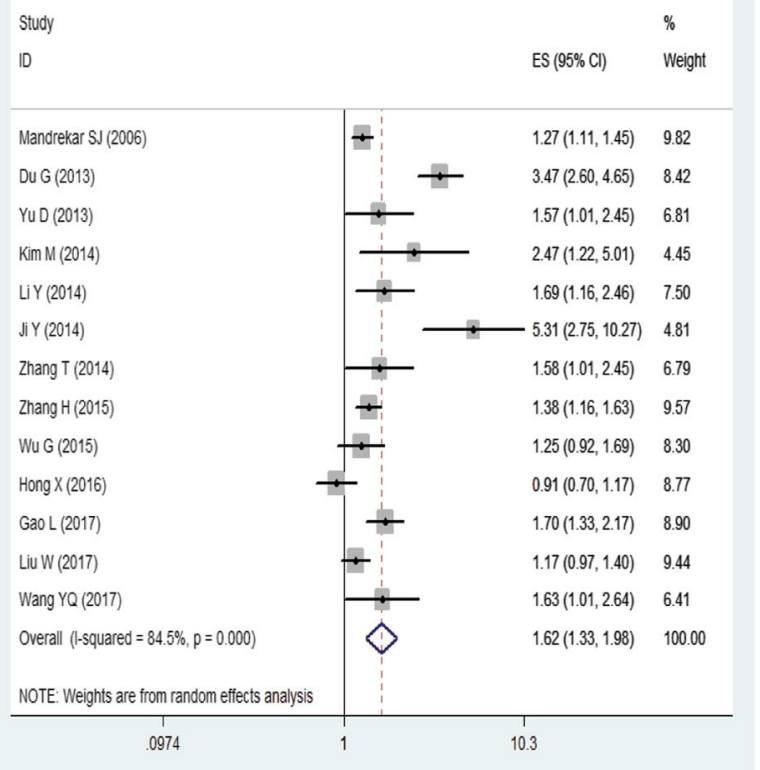

Fig. 2 Forest plot showing the HRs with 95\% Cls for the association between elevated platelet counts and OS (a) or DFS/PFS/TTP (b) 
Table 3 The results of subgroup analysis in meta-analysis of OS and DFS/PFS/TTP

\begin{tabular}{|c|c|c|c|c|c|c|c|}
\hline & Subgroup & No. of & HR $(95 \% \mathrm{Cl})$ & $P$ & Heterog & & Model \\
\hline & & & & & $1^{2}$ & $P_{h}$ & \\
\hline OS & Analysis of variable & & & & & & \\
\hline & Multivariate & 28 & $1.47(1.31-1.66)$ & $<0.001$ & $80.60 \%$ & $<0.001$ & Random \\
\hline & Univariate & 11 & $1.62(1.33-1.99)$ & $<0.001$ & $81.70 \%$ & $<0.001$ & Random \\
\hline & Ethnicity & & & & & & \\
\hline & Asian & 22 & $1.54(1.32-1.80)$ & $<0.001$ & $89.80 \%$ & $<0.001$ & Random \\
\hline & non-Asian & 17 & $1.42(1.32-1.53)$ & 0.063 & $37.00 \%$ & 0.063 & Fixed \\
\hline & Tumor stage & & & & & & \\
\hline & $|-|||$ & 9 & $1.52(1.22-1.89)$ & $<0.001$ & $89.00 \%$ & $<0.001$ & Random \\
\hline & III-IV & 8 & $1.70(1.26-2.29)$ & $<0.001$ & $85.80 \%$ & $<0.001$ & Random \\
\hline & I-IV & 15 & $1.37(1.26-1.49)$ & 0.066 & $38.20 \%$ & 0.066 & Fixed \\
\hline & Histology & & & & & & \\
\hline & NSCLC & 29 & $1.58(1.38-1.82)$ & $<0.001$ & $89.80 \%$ & $<0.001$ & Random \\
\hline & SCLC & 2 & $1.64(0.55-4.87)$ & 0.008 & $85.60 \%$ & 0.008 & Random \\
\hline & NSCLC+SCLC & 8 & $1.39(1.14-1.70)$ & 0.036 & $53.40 \%$ & 0.036 & Random \\
\hline & cut-off value & & & & & & \\
\hline & $<300 \times 10 \wedge 9 / L$ & 7 & $1.64(1.25-2.15)$ & 0.024 & $58.80 \%$ & 0.024 & Random \\
\hline & $300 \times 10^{\wedge} 9 / \mathrm{L} \leq$ cut-off value $<400 \times 10 \wedge 9 / \mathrm{L}$ & 18 & $1.40(1.27-1.55)$ & 0.002 & $55.40 \%$ & 0.002 & Random \\
\hline & $\geq 400 \times 10 \wedge 9 / L$ & 13 & $1.73(1.35-2.21)$ & $<0.001$ & $77.90 \%$ & $<0.001$ & Random \\
\hline & Quality score & & & & & & \\
\hline & $>6$ & 23 & $1.59(1.36-1.85)$ & $<0.001$ & $91.20 \%$ & $<0.001$ & Random \\
\hline & $\leq 6$ & 16 & $1.30(1.19-1.41)$ & 0.015 & $48.60 \%$ & 0.015 & Fixed \\
\hline DFS/PFS/TTP & Analysis of variable & & & & & & \\
\hline & Multivariate & 7 & $1.66(1.14-2.42)$ & $<0.001$ & $84.40 \%$ & $<0.001$ & Random \\
\hline & Univariate & 6 & $1.63(1.28-2.09)$ & $<0.001$ & $85.50 \%$ & $<0.001$ & Random \\
\hline & Ethnicity & & & & & & \\
\hline & Asian & 12 & $1.68(1.33-2.12)$ & $<0.001$ & $85.10 \%$ & $<0.001$ & Random \\
\hline & non-Asian & 1 & - & - & - & - & - \\
\hline & Tumor stage & & & & & & \\
\hline & $|-|||$ & 6 & $1.40(1.26-1.55)$ & 0.097 & $46.30 \%$ & 0.097 & Fixed \\
\hline & III-IV & 4 & $1.74(1.09-2.78)$ & $<0.001$ & $92.50 \%$ & $<0.001$ & Random \\
\hline & Histology & & & & & & \\
\hline & NSCLC & 12 & $1.71(1.40-2.09)$ & $<0.001$ & $83.00 \%$ & $<0.001$ & Random \\
\hline & $\mathrm{SCLC}$ & 1 & - & - & - & - & - \\
\hline & cut-off value & & & & & & \\
\hline & $<300 \times 10^{\wedge} 9 / \mathrm{L}$ & 4 & $1.47(1.21-1.78)$ & 0.584 & $0.00 \%$ & 0.584 & Fixed \\
\hline & $300 \times 10^{\wedge} 9 / \mathrm{L} \leq$ cut-off value $<400 \times 10^{\wedge} 9 / \mathrm{L}$ & 7 & $1.42(1.15-1.74)$ & $<0.001$ & $81.40 \%$ & $<0.001$ & Random \\
\hline & $\geq 400 \times 10 \wedge 9 / L$ & 2 & $3.30(2.52-4.32)$ & 0.383 & $0.00 \%$ & 0.383 & Fixed \\
\hline & Quality score & & & & & & \\
\hline & $>6$ & 11 & $1.77(1.42-2.20)$ & $<0.001$ & $84.30 \%$ & $<0.001$ & Random \\
\hline & $\leq 6$ & 2 & $1.04(0.85-1.26)$ & 0.114 & 0.599 & 0.114 & Fixed \\
\hline
\end{tabular}


stage I-III disease subgroup $(P=0.097)$, studies with a quality score $\leq 6(P=0.114)$, platelet count $>400$ subgroup $(P=0.383)$, and platelet count $<300$ subgroup $(P=0.584)$.

\section{Publication bias and sensitivity analysis}

As shown in Fig. 3, the funnel plot was symmetrical. Based on Begg's test $(P=0.866)$ and Egger's regression test $(P=$ $0.376)$, no significant publication bias was found.

Furthermore, we performed sensitivity analysis to evaluate the reliability of our results. The corresponding pooled HR values were not significantly impacted, indicating the robustness of our conclusions (Fig. 4).

\section{Discussion}

Cancer is undoubtedly one of the most serious public health problems. In the past few years, antidiuretic hormone (ADH), tumour necrosis factor alpha (TNF- $\alpha$ ), $\mathrm{NF}-\mathrm{kB} / \mathrm{p} 65, \mathrm{COX}-2$ and thyroid transcription factor-1 (TTF-1) have been reported to be associated with the prognosis of lung cancer. However, their specificity and sensitivity in prognosis are still not satisfactory. Therefore, the exploration of new lung cancer prognostic markers is of great significance for clinicians to take targeted measures and improve the prognosis of patients.

In recent years, it has been observed that some systemic inflammation indicators, such as the neutrophilto-lymphocyte ratio (NLR) [61], platelet-to-lymphocyte ratio (PLR) [62], Glasgow prognostic score (GPS) [63], Prognostic Index (PI) and Prognostic Nutritional Index (PNI) [64], play important roles in tumorigenesis and development and can be considered predictors of prognosis. In the 1960s, Richard B observed that the platelet count is elevated in patients with cancers compared to

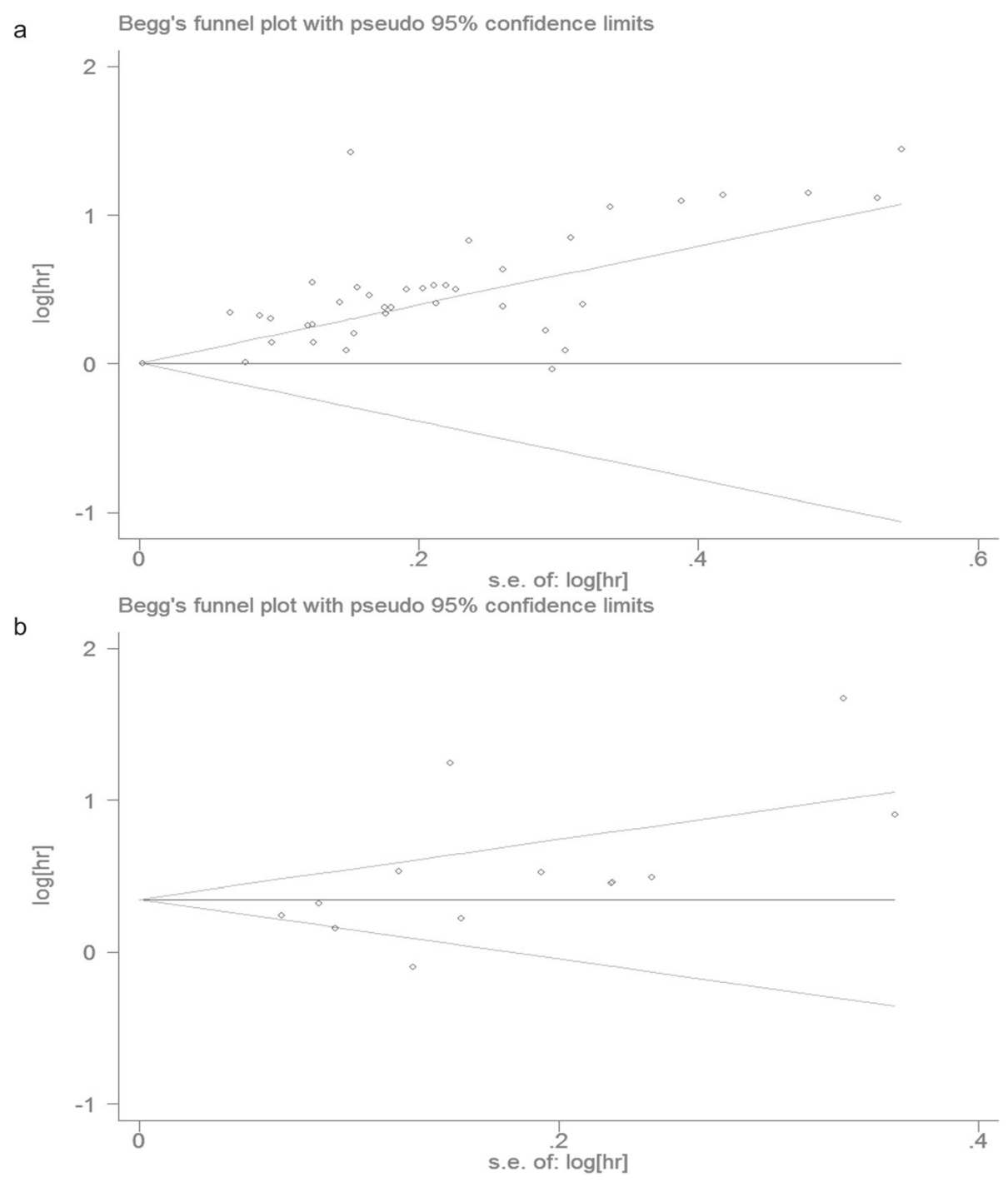

Fig. 3 Begg's funnel plots and Egger's test evaluating possible publication bias for (a) OS; (b) DFS/PFS/TTP 

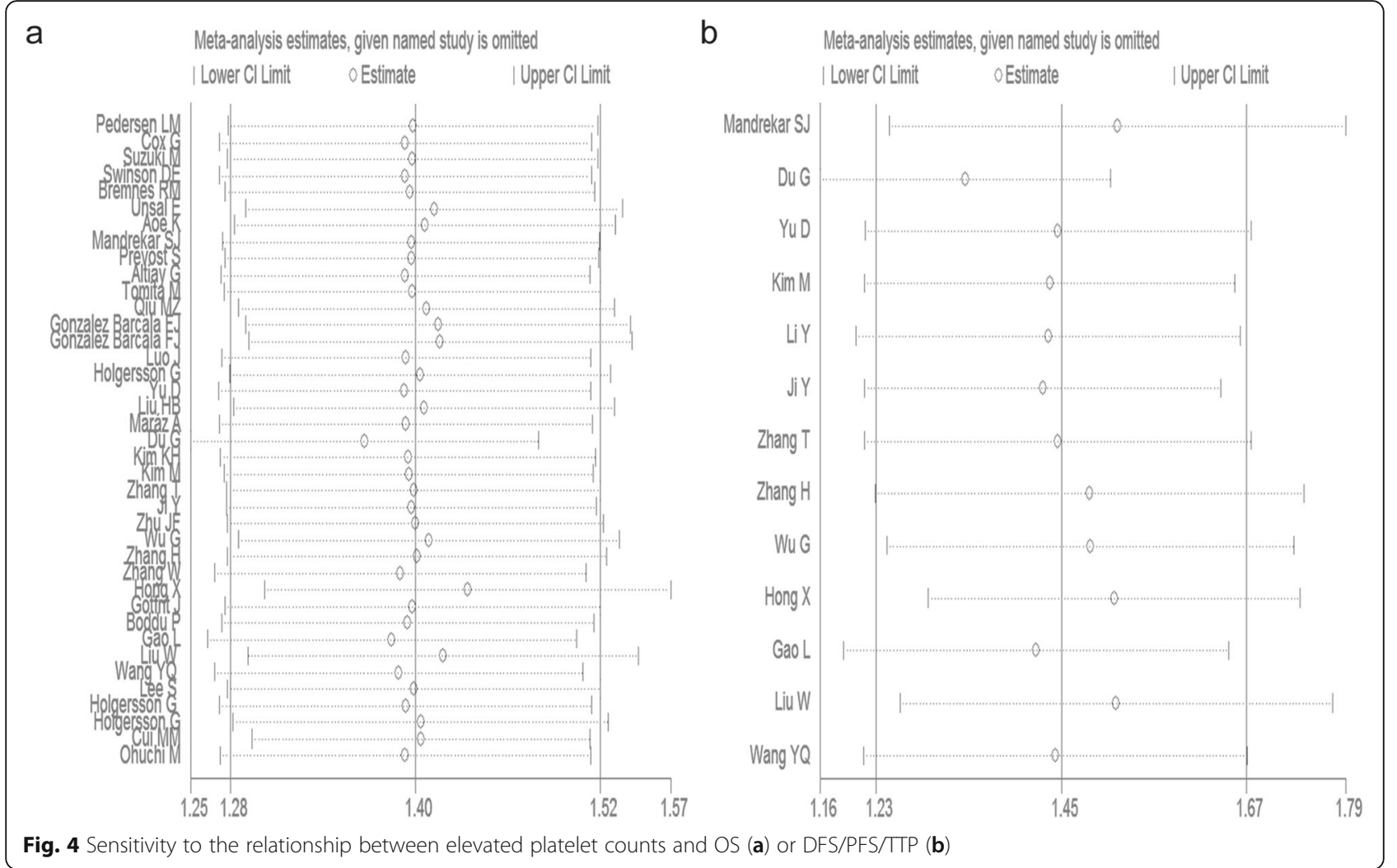

Fig. 4 Sensitivity to the relationship between elevated platelet counts and OS (a) or DFS/PFS/TTP (b)

those with nonmalignant diseases [5]. Accumulating evidence suggests that elevated platelet counts are associated with various cancers, such as colorectal cancer, lung cancer, and endometrial carcinoma $[12,65,66]$. Platelets sustain proliferative signalling, resist cell death, and induce tumour angiogenesis [67]. Additionally, platelets activate the TGF- $\beta /$ Smad and NF- $\mathrm{kB}$ pathways, further promoting tumour migration and invasion [68]. Moreover, as immune cells [69], platelets release TGF- $\beta$, reducing the expression of NKG2D and weakening the role of natural killer (NK) cells [70]. Platelets could be a prognostic predictor used in the clinic. Recently, several studies confirming the prognostic value of platelet count in lung cancer have been carried out; however, the results were inconsistent. Therefore, we conducted a meta-analysis to determine the precise role of platelet counts in lung cancer.

We combined the outcomes of 40 studies with 16,696 patients, suggesting that elevated platelet counts are a poor predictor of OS and DFS/PFS/TTP in lung cancer patients. In our subgroup analysis, elevated platelet counts were significantly associated with poor OS and DFS/PFS/TTP in diverse subgroups, such as Asian populations, tumour stages I-III, tumour stages III-IV, and studies with quality scores $>6$. However, the cut-off value of the platelet count was variable. We found that elevated platelet counts were significantly associated with poor OS and DFS/PFS/TTP when the cut-off value was between 300 and 400, while the cut-off value of > 400 did not have a relationship with poor DFS/PFS/ TTP. Overall, the cut-off value of plate count between 300 and 400 can separate patients well for OS and DFS/ PFS/TTP and should be used as a prognostic biomarker in clinical use, which is more precise than the findings of the previous meta-analysis [71]. Compared to the previous meta-analysis [71], our results are more comprehensive and accurate. On the one hand, we included 40 articles in the meta-analysis, which included more new and important studies, increasing the analytical capability of the analysis. On the other hand, a more detailed subgroup analysis was performed. In addition to race and the cut-off value of platelet count, we also investigated the prognostic role of platelet count in different tumour stages, histology and quality scores. Additionally, we discussed the association between platelets and OS as well as DFS/PFS/TTP, while the previous metaanalysis studied only the significance in OS.

However, there are some limitations of this study that deserve to be mentioned. First, the studies included in our meta-analysis are retrospective studies and are therefore more likely to have selection bias. Second, although the publication bias and sensitivity analyses confirmed the credibility of our analysis, heterogeneity still existed in this meta-analysis due to several factors, such 
as patient characteristics, sample size, and adjuvant therapy, which were not included in our analysis. Moreover, the cut-off value for definition of the elevated platelet counts differed among the studies. Most of the studies used 300-400 as the cut-off value, while several others used $<300$ or $>400$ as the cut-off value of platelet count to assess the prognosis, which might lead to betweenstudy heterogeneity. Last, platelet count could be affected by several factors, such as thrombosis, hypertension, splenic diseases, blood coagulation disorders, myeloproliferative disease, infection and drugs. Therefore, platelet count cannot play a prognostic role if patients have these diseases mentioned above.

\section{Conclusions}

In conclusion, our meta-analysis revealed that elevated pretreatment platelet counts are related to poor OS and DFS/PFS/TTP in lung cancer patients and are an independent prognostic predictor of lung cancer patients. Considering the limitations, large-scale prospective studies and a validation study are warranted to confirm our results.

\section{Supplementary information}

Supplementary information accompanies this paper at https://doi.org/10. 1186/s12890-020-1139-5.

Additional file 1. PRISMA checklist.

\section{Abbreviations}

DFS: Disease-free survival; PFS: Progression-free survival; TTP: Time to progression; OS: Overall survival; HR: Hazard ratio; Cls: Confidence intervals; NSCLC: Non-small-cell lung cancer; SCLC: Small cell lung cancer; NOS: Newcastle-Ottawa Scale; NLR: Neutrophil-to-lymphocyte ratio; PLR: Platelet-to-lymphocyte ratio; GPS: Glasgow prognostic score; PI: Prognostic Index; PNI: Prognostic Nutritional Index

\section{Acknowledgements}

The authors thank all people who responded to our screening and analysis.

\section{Authors' contributions}

$Z H, Y Y$ and $Q Y Y$ were involved in the study design, literature search, review of the articles, extraction of the data, statistical analysis and writing of the manuscript. YL and LQ contributed to the study design, literature search, review of the articles, interpretation of the data and revision of the manuscript. FSR and GW participated in the study design, interpretation of the data and revision of the manuscript. All authors read and approved the final manuscript.

\section{Funding}

This study was supported by the National Natural Science Foundation of China (No. 81601998). The funder had no role in the study design, data collection and analysis, decision to publish, or preparation of the work.

\section{Availability of data and materials}

The data used and/or analysed during the current study available from the corresponding author on reasonable request.

Ethics approval and consent to participate Not applicable.
Consent for publication

Not applicable.

\section{Competing interests}

The authors declare that they have no competing interests.

\section{Author details}

${ }^{1}$ Department of Respiratory and Critical Care Medicine, Nanjing First Hospital, Nanjing Medical University, 68 Changle road, Nanjing 210006, Jiangsu, China. ${ }^{2}$ Department of Pulmonary and Critical Care Medicine, The Affiliated Jiangning Hospital of Nanjing Medical University, Nanjing 210006, Jiangsu, China.

Received: 16 October 2019 Accepted: 7 April 2020

Published online: 20 April 2020

\section{References}

1. Bray F, Ferlay J, Soerjomataram I, et al. Global cancer statistics 2018: GLOBOCAN estimates of incidence and mortality worldwide for 36 cancers in 185 countries. CA Cancer J Clin. 2019;68:394-424.

2. Alberg AJ, Brock MV, Samet JM. Epidemiology of lung cancer: looking to the future. J Clin Oncol Off J Am Soc Clin Oncol. 2005;23:3175-85.

3. Moro-Sibilot D, Smit E, de Castro CJ, et al. Outcomes and resource use of non-small cell lung cancer (NSCLC) patients treated with first-line platinumbased chemotherapy across Europe: FRAME prospective observational study. Lung Cancer. 2015;88:215-22.

4. Paesmans $M$, Sculier JP, Libert $P$, et al. Prognostic factors for survival in advanced non-small-cell lung cancer: univariate and multivariate analyses including recursive partitioning and amalgamation algorithms in 1,052 patients. The European lung Cancer working party. J Clin Oncol Off J Am Soc Clin Oncol. 1995;13:1221-30.

5. Davis RB, Theologieds A, Kennedy B. Comparative Studies of Blood Coagulation and Platelet Aggregation in Patients with Cancer and Nonmalignant Diseases. Ann Intern Med. 1969;71(1):67-80. https://doi.org/ 10.7326/0003-4819-71-1-67.

6. Wang $Y$, Reheman A, Spring C, et al. Plasma fibronectin supports hemostasis and regulates thrombosis. J Clin Invest. 2014;124:4281-93.

7. Bastida E, Ordinas A. Platelet contribution to the formation of metastatic foci: the role of cancer cell-induced platelet activation. Haemostasis. 1988; 18:29-36.

8. Stone RL, Nick AM, McNeish IA, et al. Paraneoplastic thrombocytosis in ovarian cancer. N Engl J Med. 2012;366:610-8.

9. Lin RJ, Afshar-Kharghan V, Schafer Al. Paraneoplastic thrombocytosis: the secrets of tumor self-promotion. Blood. 2014;124:184-7.

10. Baranyai Z, Krzystanek M, Jósa V, et al. The comparison of thrombocytosis and platelet-lymphocyte ratio as potential prognostic markers in colorectal cancer. Thromb Haemost. 2014:111:483-90.

11. Sasaki K, Kawai K, Tsuno NH, Sunami E, Kitayama J. Impact of preoperative thrombocytosis on the survival of patients with primary colorectal cancer. World J Surg. 2012;36:192-200.

12. Zhang $X$, Ran $Y$. Prognostic role of elevated platelet count in patients with lung cancer: a systematic review and meta-analysis. Int J Clin Exp Med. 2015;8:5379-87.

13. Bensalah $\mathrm{K}$, Leray $\mathrm{E}$, Fergelot $\mathrm{P}$, et al. Prognostic value of thrombocytosis in renal cell carcinoma. J Urol. 2006;175:859-63.

14. Wang $\mathrm{YH}$, Kang JK, Zhi YF, et al. The pretreatment thrombocytosis as one of prognostic factors for gastric cancer: A systematic review and meta-analysis. Int J Surg. 2018:53:304-11.

15. Wu YY, Xi Z, Qin YY, Qin JQ, Lin FQ. Mean platelet volume/platelet count ratio in colorectal cancer: a retrospective clinical study. BMC Cancer. 2019; 19:314.

16. Scheiner B, Kirstein M, Popp S, et al. Association of Platelet Count and Mean Platelet Volume with overall survival in patients with cirrhosis and Unresectable hepatocellular carcinoma. Liver Cancer. 2019;8:203-17.

17. Qiu MZ, Xu RH, Ruan DY, et al. Incidence of anemia, leukocytosis, and thrombocytosis in patients with solid tumors in China. Tumor Biol. 2010;31: 633-41.

18. Lee S, Eo W, Jeon H, Park S, Chae J. Prognostic significance of host-related biomarkers for survival in patients with advanced non-small cell lung Cancer. J Cancer. 2017;8:2974-83. 
19. Gonzalez Barcala FJ, Garcia Prim JM, Moldes Rodriguez M, et al. Platelet count: association with prognosis in lung cancer. Med Oncol. 2010;27:357-62.

20. Stang A. Critical evaluation of the Newcastle-Ottawa scale for the assessment of the quality of nonrandomized studies in meta-analyses. Eur J Epidemiol. 2010;25:603-5.

21. Higgins JPT, Thompson SG, Deeks JJ, Altman DG. Measuring inconsistency in meta-analyses. Cochrane Database Syst Rev. 2018. https://doi.org/10. 1002/14651858 CD011729. pub2.

22. Kontopantelis $E_{1}$ Reeves D. Performance of statistical methods for metaanalysis when true study effects are non-normally distributed: a simulation study. Stat Methods Med Res. 2012;21:409-26.

23. Brockwell SE, Gordon IR. A comparison of statistical methods for metaanalysis. Stat Med. 2001;20:825-40.

24. Egger M, Davey Smith G, Schneider M, Minder C. Bias in meta-analysis detected by a simple, graphical test. BMJ (Clinical research ed). 1997;315: 629-34

25. Wang J, Sheng Z, Yang W, Cai Y. Elevated serum concentration of Chitinase 3 -like 1 is an independent prognostic biomarker for poor survival in lung Cancer patients. Cell Physiol Biochem. 2016;38:461-8.

26. Møller Pedersen L, Milman N. Prognostic significance of thrombocytosis in patients with primary lung cancer. Eur Respir J. 1996;9:1826-30.

27. Cox G, Walker RA, Andi A, Steward WP, O'Byren KJ. Prognostic significance of platelet and microvessel counts in operable non-small cell lung cancer. Lung Cancer. 2000;29:169-77.

28. Suzuki M, lizasa T, Ko E, et al. Serum endostatin correlates with progression and prognosis of non-small cell lung cancer. Lung Cancer. 2002;35:29-34.

29. Swinson DE, Jones $J \mathrm{~L}$, Richardson D, et al. Carbonic anhydrase IX expression, a novel surrogate marker of tumor hypoxia, is associated with a poor prognosis in non-small-cell lung cancer. J Clin Oncol. 2003; 21:473-82.

30. Hong $X, X u$ Q, Yang Z, et al. The value of prognostic factors in small cell lung cancer: results from a randomised multicenter study with minimum 5 year follow-up. Lung Cancer. 2003;39:303-13.

31. Ünsal E, Atalay F, Atikcan S, Yilmaz A. Prognostic significance of hemostatic parameters in patients with lung cancer. Respir Med. 2004;98:93-8.

32. Aoe K, Hiraki A, Ueoka $\mathrm{H}$, et al. Thrombocytosis as a useful prognostic indicator in patients with lung cancer. Respiration. 2004;71:170-3.

33. Mandrekar SJ, Schild SE, Hillman SL, et al. A prognostic model for advanced stage nonsmall cell lung cancer. Pooled analysis of north central Cancer treatment group trials. Cancer. 2006;107:781-92.

34. Pre'vost S, Boucher L, Larive'e P, Boileau R, Be'nard F. Bone Marrow Hypermetabolism on 18F-FDG PET as a Survival Prognostic Factor in NonSmall Cell Lung Cancer. J Nucl Med. 2006;47(4):559-65.

35. Altiay G, Ciftci A, Demir M, et al. High plasma D-dimer level is associated with decreased survival in patients with lung cancer. Clin Oncol (R Coll Radiol). 2007;19:494-8

36. Tomita M, Shimizu T, Hara M, Ayabe T, Onitsuka T. Prognostic impact of thrombocytosis in resectable non-small cell lung cancer. Interact Cardiovasc Thorac Surg. 2008;7:613-5

37. Luo J, Chen YJ, Narsavage GL, Ducatman A. Predictors of survival in patients with non-small cell lung cancer. Oncol Nurs Forum. 2012;39:609-16.

38. Holgersson G, Sandelin M, Hoye E, Bergstrom S, Henriksson R, Ekman S, et al. Swedish lung cancer radiation study group: the prognostic value of anaemia, thrombocytosis and leukocytosis at time of diagnosis in patients with non-small cell lung cancer. Med Oncol. 2012;29:3176-82.

39. Yu D, Liu B, Zhang L, Du K. Platelet count predicts prognosis in operable non-small cell lung cancer. Exp Ther Med. 2013;5:1351-4.

40. Liu HB, Gu XL, Ma XQ, et al. Preoperative platelet count in predicting lymph node metastasis and prognosis in patients with non-small cell lung cancer. Neoplasma. 2012;60:203-8.

41. Gangjun D, Yang Y, Yaping Z, et al. Thrombocytosis and immunohistochemical expression of connexin 43 at diagnosis predict survival in advanced non-small-cell lung cancer treated with cisplatin-based chemotherapy. Cancer Chemother Pharmacol. 2013;71:893-904.

42. Maráz A, Furák J, Varga Z, Kahán Z, Tiszlavicz L, Tiszlavicz L. Thrombocytosis Has a Negative Prognostic Value in Lung Cancer. Anticancer Res. 2013;33(4): 1725-9.

43. Li Y, Miao LY, Xiao YL, Cai HR, Zhang DP. Elevated platelets enhance cancer cell migration, promote hematogenous metastasis and associate with a poor prognosis in advanced non-small cell lung cancer cases. Asian Pac J Cancer Prev. 2014;15:139-43.
44. Zhang T, Jiang Y, Qu X, et al. Evaluation of preoperative hematologic markers as prognostic factors and establishment of novel risk stratification in resected pNO non-small-cell lung cancer. PLoS One. 2014;9:e111494. https://doi.org/10.1371/journal. pone. 0111494

45. Zhu JF, Cai L, Zhang XW, et al. High plasma fibrinogen concentration and platelet count unfavorably impact survival in non-small cell lung cancer patients with brain metastases. Chin J Cancer. 2014;33:96-104.

46. Kim M, Chang $\mathrm{H}$, Yang $\mathrm{HC}$, et al. Preoperative thrombocytosis is a significant unfavorable prognostic factor for patients with resectable non-small cell lung cancer. World J Surg Oncol. 2014. https://doi.org/10.1186/1477-7819-12-37.

47. Kim KH, Park TY, Lee JY, et al. Prognostic significance of initial platelet counts and fibrinogen level in advanced non-small cell lung cancer. J Korean Med Sci. 2014;29:507-11.

48. Wu G, Yao Y, Bai C, et al. Combination of platelet to lymphocyte ratio and neutrophil to lymphocyte ratio is a useful prognostic factor in advanced non-small cell lung cancer patients. Thorac Cancer. 2015;6:275-87.

49. Zhang W, Yu C, Huang B, et al. Correlation between bone metastasis and thrombocytosis in pulmonary adenocarcinoma patients. Oncol Lett. 2015;9: 762-8.

50. Ji Y, Sheng L, Du X, Qiu G, Su D. Elevated platelet count is a strong predictor of poor prognosis in stage I non-small cell lung cancer patients. Platelets. 2015;26:138-42.

51. Zhang $H$, Zhang $L$, Zhu $K$, et al. Prognostic significance of combination of preoperative platelet count and neutrophil-lymphocyte ratio (COP-NLR) in patients with non-small cell lung Cancer: based on a large cohort study. PLoS One. 2015;10:e0126496.

52. Gotfrit J, Zhang T, Zanon-Heacock S, Wheatley-Price P. Patients with advanced non-small cell lung Cancer requiring inpatient medical oncology consultation: characteristics, referral patterns, and outcomes. Clin Lung Cancer. 2016;17:292-300.

53. Hong X, Xu Q, Yang Z, et al. The value of prognostic factors in Chinese patients with small cell lung cancer: a retrospective study of 999 patients. Clin Respir J. 2018;12:433-47.

54. Boddu P, Villlines D, Aklilu M. Paraneoplastic leukocytosis and thrombocytosis as prognostic biomarkers in non-small cell lung Cancer. Zhongguo Fei Ai Za Zhi. 2016;19:725-30.

55. Wu G, Yao Y, Bai C, et al. Combination of platelet count and lymphocyte to monocyte ratio is a prognostic factor in patients undergoing surgery for nonsmall cell lung cancer. Thorac Cancer. 2015. https://doi.org/10.1111/ 1759-7714.12178.

56. Ohuchi M, Inoue S, Ozaki Y, Ueda K. Platelet count and mean platelet volume are associated with not only bone, soft tissue, and lymph node metastases but also with malignant pleural effusion in lung cancer patients. Neoplasma. 2017;64:140-7.

57. Gao L, Zhang H, Zhang B, Zhang L, Wang C. Prognostic value of combination of preoperative platelet count and mean platelet volume in patients with resectable non-small cell lung cancer. Oncotarget. 2017. https://doi.org/10.18632/oncotarget.14921.

58. Wang YQ, Zhi QJ, Wang XY, Yue DS, Li K, Jiang RC. Prognostic value of combined platelet, fibrinogen, neutrophil to lymphocyte ratio and platelet to lymphocyte ratio in patients with lung adenosquamous cancer. Oncol Lett. 2017;14:4331-8.

59. Holgersson G, Bergqvist M, Nilsson J, Thureson M, Harmenberg J, Bergstrom S. The Prognostic Value of Pre-Treatment Leukocytosis in Patients with Previously Treated, Stage IIIB/IV Non-Small Cell Lung Cancer Treated with the IGF-1R Pathway Modulator AXL1717 or Docetaxel; a Retrospective Analysis of a Phase II Trial. Asian Pac J Cancer Prev. 2017;18:1555-60.

60. Holgersson G, Bergstrom S, Hallqvist A, et al. The prognostic value of pretreatment thrombocytosis in two cohorts of patients with non-small cell lung cancer treated with curatively intended chemoradiotherapy. Neoplasma. 2017;64:909-15.

61. Gu XB, Tian T, Tian T, Tian XJ, Zhang XJ. Prognostic significance of neutrophil-to-lymphocyte ratio in non-small cell lung cancer: a metaanalysis. Sci Rep. 2015;5:12493.

62. Zhang H, Gao L, Zhang B, Zhang L, Wang C. Prognostic value of platelet to lymphocyte ratio in non-small cell lung cancer: a systematic review and meta-analysis. Sci Rep. 2016. https://doi.org/10.1038/srep22618.

63. Laird BJ, Kaasa S, McMillan DC, et al. Prognostic factors in patients with advanced cancer: a comparison of clinicopathological factors and the development of an inflammation-based prognostic system. Clin Cancer Res. 2013;19:5456-64. 
64. Proctor MJ, Morrison DS, Talwar D, et al. A comparison of inflammationbased prognostic scores in patients with cancer. A Glasgow Inflammation Outcome Study. Eur I Cancer. 2011;47:2633-41.

65. Nie D, Yang E, Li Z. Pretreatment thrombocytosis predict poor prognosis in patients with endometrial carcinoma: a systematic review and metaanalysis. BMC Cancer. 2019;19:73. https://doi.org/10.1186/s12885-018-5264-y.

66. Rao XD, Zhang H, Xu ZS, Cheng H, Shen W, Wang XP. Poor prognostic role of the pretreatment platelet counts in colorectal cancer: a meta-analysis. Medicine. 2018. https://doi.org/10.1097/MD.0000000000010831.

67. Xu XR, Yousef GM, Ni H. Cancer and platelet crosstalk: opportunities and challenges for aspirin and other antiplatelet agents. Blood. 2018;131:1777-89.

68. Labelle M, Begum S, Hynes RO. Direct signaling between platelets and cancer cells induces an epithelial-mesenchymal-like transition and promotes metastasis. Cancer Cell. 2011;20:576-90.

69. Xu XR, Zhang D, Oswald BE, et al. Platelets are versatile cells: new discoveries in hemostasis, thrombosis, immune responses, tumor metastasis and beyond. Crit Rev Clin Lab Sci. 2016:53:409-30.

70. Bauer S, Groh V, Wu J, et al. Activation of NK cells and T cells by NKG2D, a receptor for stress-inducible MICA. Science. 1999;285:727-9.

71. Zhang X, Ran Y. Prognostic role of elevated platelet count in patients with lung cancer- a systematic review and meta-analysis. Int J Clin Exp Med. 2015:8(4):5379-87.

\section{Publisher's Note}

Springer Nature remains neutral with regard to jurisdictional claims in published maps and institutional affiliations.

Ready to submit your research? Choose BMC and benefit from:

- fast, convenient online submission

- thorough peer review by experienced researchers in your field

- rapid publication on acceptance

- support for research data, including large and complex data types

- gold Open Access which fosters wider collaboration and increased citations

- maximum visibility for your research: over $100 \mathrm{M}$ website views per year

At $\mathrm{BMC}$, research is always in progress.

Learn more biomedcentral.com/submissions 